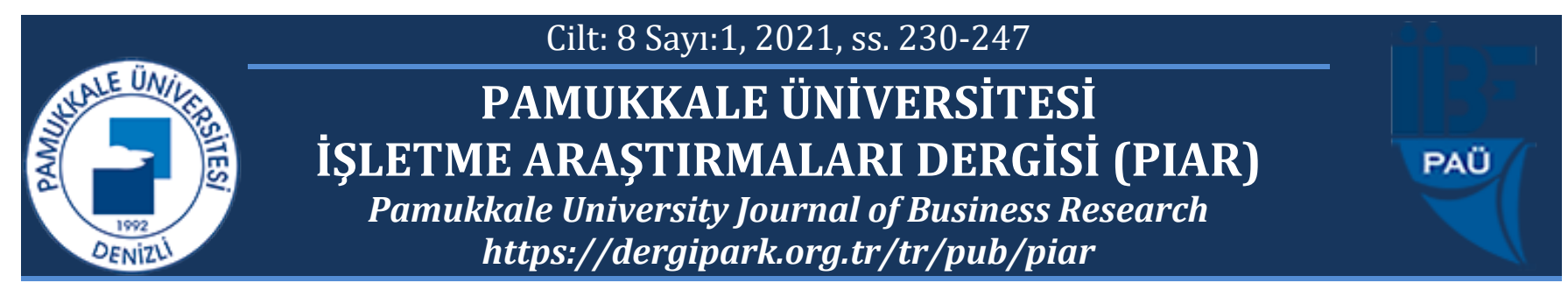

\title{
LGBT Bireylerin Tüketici Satın Alma Tarzı
}

\section{Consumer Purchase Style of LGBT Individuals}

\section{Duygu KOÇOĞLU ${ }^{*}$}

\section{Tuğçe AKSOY ERKATRANCI ${ }^{2}$}

1 Pamukkale Üniversitesi, İİB, dkocoglu@pau.edu.tr, https://orcid.org/0000-0003-4576-0567

2 Pamukkale Üniversitesi, İ̈BF, tugceaksoy88@gmail.com, https://orcid.org/0000-0001-6217-1364

* Yazışılan Yazar/Corresponding author

Makale Geliş/Received: 13 Nisan 2021

Öz

Eskiden beri varolan, günümüzde daha rahat telaffuz edilen LGBT bireyler artık büyüyen bir pazar bölümü olarak kabul edilmektedir. Ancak birçok tüketici araştırmasında cinsiyet değişkeni sadece kadın ve erkek gruplar arasında ele alınmaktadır. Bu çalışmanın amacı, LGBT bireylerin satm alma tarzlarm tespit etmek ve kozmetik, giyim, eğlence harcama davranışın değerlendirmek, tüketici olarak hetoroseksüel bireyler ile farklılıklarını ortaya koymaktır. Araştırma sonucunda heteroseksüeller ile LGBT bireyler arasinda kadın katılımcılarda kalite odaklılık ve çeşit karmaşasında, erkek katılımcilarda ise sadece marka odaklılikta anlaml farklılık bulunmuştur. Eğlence harcamasında sadece erkek gruplar arasında anlamlı farklılık ortaya çıkmıştır.

Anahtar kelimeler: LGBT Tüketici, Cinsel Yönelim, Satın Alma Tarzı.

JEL kodları: M31
Makale Kabul/Accepted: 5 Haziran 2021

\begin{abstract}
LGBT individuals, which have existed for a long time but are more pronounced today, are now accepted as a growing market segment. However, in many consumer studies, the gender variable is only considered between male and female groups. The aim of this study is to determine the Purchase Style of LGBT individuals, to evaluate the cosmetics, clothing, entertainment expenditure behavior, and to reveal the differences between heterosexual individuals as consumers. As a result of the study, a significant difference was found between heterosexual and LGBT individuals in qualityorientation and diversity complexity in female participants, and only in brand focus among male participants. The only significant difference in this research was found between male groups in entertainment expenditure.
\end{abstract}

Keywords: LGBT Consumer, Sexual Orientation, Purchase Style.

JEL codes: M31 


\section{GİRIŞ}

Günümüzde insanların yaşam tarzının değişmesi, toplum baskısının azalmasıyla birlikte daha fazla konuşulan ve tartışılan LGBT bireyler (lezbiyen, eşcinsel, biseksüel, transseksüel) kurdukları birliklerle ve örgütlenme çabalarıla toplumda daha fazla farkındalık yaratmışlardır. LGBT bireylerle ilgili pazarlama alanında yapılan çalışmalara bakıldı̆̆ında çok fazla literatür olmadığı göze çarpmaktadır. Toplumsal önyargılar, LGBT bireylerin yok sayılması, bu guruplara erişimin zor olması konuyla ilgili çalışmaların az olmasına neden olmaktadır. Homofobi olarak adlandırılan LGBT bireylere karşı nefret ve hoşnutsuzluk gibi olumsuz, insani olmayan tutumlar bazı LGBT bireylerin içe kapanmasına yol açmakta araştırmacıların işini zorlaştırmaktadır. LGBT bireylerin gelişen bir pazar bölümü olarak dikkate alınması ve araştırılması gereklidir. ABD merkezli bir araştırma şirketinin yapmış olduğu araştırmaya göre, dünya genelinde giderek daha fazla kişi eşcinselliğin kabul görmesi gerektiği görüşündedir. ABD, Güney Kore, Japonya, Güney Afrika, Almanya ve İngiltere'de gerçekleştirilen, 2002-2019 yıllarının karşılaştırıldı̆̆ bireylerin topluma dahil olduğunu düşünenlerin oranında artış tespit edilmiştir (https://www.dw.com/tr/dünyada-eşcinselligin-kabul-görme-oranı). Biyolojik cinsiyetine göre kadın veya erkek olarak tanımlanmaktan rahatsızlık duyan LGBT bireylerin varlığının kabul edilmesinin ve satın alma tarzının tespit edilmesinin, pazarlama literatürüne katkı sağlıyacağı düşünülmektedir.

\section{CINSIYYET VE CINNSEL YÖNELIM}

Literatürde araştırmacıların bir kısmı cinsiyet ve toplumsal cinsiyet kavramlarını birbirlerinin yerine kullanırken, diğerleri cinsiyet kavramını üç farklı şekilde; biyolojik cinsiyet (kadın/erkek), toplumsal cinsiyet ve cinsel kimlik (maskulen/feminen) olarak ele almaktadır. Bu çalışmada öncelikle iç içe geçmiş cinsiyet kavramları ayrıştırılıp, açıklanmaya çalışılacaktır. Biyolojik cinsiyet (sex), kişinin kadın ya da erkek olarak gösterdiği genetik, fizyolojik ve biyolojik özellikleridir. Bebekler doğduğunda sahip oldukları cinsel organa göre kadın ya da erkek cinsiyet grubuna tanımlanır (Dökmen, 2004: 5,6). Türk Dil Kurumu'nun yaptığı tanıma göre "bireye, üreme işinde ayrı bir rol veren ve erkekle dişiyi ayırt ettiren yaradılış özelliği, eşey, cinslik, seks" cinsiyet olarak belirtilmiştir. Toplumsal cinsiyet (gender) terimi ise, "1968'de toplumsal cinsiyetin biyolojik cinsiyetten (sex) nasıl farklı olabileceğini göstermek için Robert Stoller tarafından ortaya atılmıştır" (Segal, 1992: 98). Toplumsal cinsiyet rolleri, toplum tarafından kadınlara ve erkeklere yüklenen rollerdir. Belirlenen bu roller, kadına ve erkeğe, yaşadığı toplum içerisindeki yerini, günlük yaşamda toplumun ortak beklentileri açısından nasıl davranmaları gerektiğini, hangi sorumlulukları üstleneceğini göstermektedir (Eagly vd.,2000:135). Kısacası toplumsal cinsiyet, biyolojik farklılıklarla ilgisi olmayan, kadın ve erkek olarak toplumun bizi nasıl gördüğü, nasıl algıladığı, nasıl düşündüğü ve nasıl davranmamızı beklediği ile ilgili bir kavramdır (Akın ve Demirel, 2003: 73).

Cinsiyet kimliği bireylerin biyolojik cinsiyetlerinden farklı olarak kendilerini tanımlamalarıyla ilgili olan psikolojik cinsiyettir. Bireylerin geleneksel erkeksi veya kadınsı rollerini kendi kavramlarına ne derecede dahil ettiklerini tanımlayan, çeşitli davranış kalıpları ile erkek ve kadın tutumlarındaki farklılıkları açıklamaya yönelik araştırmacılar tarafından yaygın olarak kullanılan bir kavramdır (Kagan, 1964; Kohlberg, 1966; Bem, 1974; 
Barbee vd., 1993:178). Lombardi vd., (2002: 92)’ye göre cinsiyet kimliği terimi, bireyin kendisini erkek, kadın veya bu iki kategorinin arasında ya da dışında bir kimlik olarak tanımlamasıdır. Bem (1981) cinsiyet kimliklerini belirlerken Bem Cinsiyet Rolü Envanteri'ni (BCRE) kullanmıştır. Bem Cinsiyet Rolü Envanteri'ne göre cinsiyet kimlikleri dört kategoriye ayrılmıştır; çok sayıda kadınsı ve az sayıda erkeksi özelliğe sahip olan bireyler feminen; çok sayıda erkeksi ve az sayıda kadınsı özelliğe sahip bireyler de maskülen, çok sayıda erkeksi ve çok sayıda kadınsı özelliğe sahip olan bireyler androjen olarak tanımlanmıştır. Her iki tür özellik grubundan daha azına sahip olanlar ise kayıtsız (undifferentiated) olarak adlandırılmıştır (Bem vd., 1976). Biyolojik cinsiyeti erkek olan bir kişi psikolojik cinsiyet boyutunda feminen bir tutum sergileyebilir, biyolojik cinsiyeti kadın olan bir kişi ise maskülen özelliklere sahip olabilir (Bem, 1981). Bir başka ifadeyle maskülen kadınlar olduğu gibi, feminen erkekler de vardır. Bu tanımların dişında kalan cinsel yönelimin insanlarda nasıl ortaya çıtı̆̆ına dair görüş birliği olmamakla birlikte pek çok teori ortaya atılmıştır.

Literatür 'cinsel yönelim' tartışmalarıyla doludur, ancak üstünkörü bir araştırma bile cinsel yönelim konusunda son derece farklı, çelişkili ve bazen etik açıdan rahatsız edici nitelikler ortaya çıkarmaktadır (Dembroff, 2016;1). Cinsel yönelim, erkeklere, kadınlara veya her ikisine yönelik cinsel çekiciliği ifade eder. Aynı cinse karşı cinsel olarak dürtüsü olan insanlar,"heteroseksüel olmayan" olarak ifade edilmekte ve yetişkinlerin azınlığını temsil etmektedir (Bailey vd., 2016: 45). Cinsel yönelim üç gruba ayrılmaktadır; eşcinsellik (homoseksüel), heteroseksüellik ve biseksüellik. Bu kavramlar aşağıda kısaca açıklanmıştır:

Eşcinsellik (homoseksüellik), kendileriyle aynı cinsiyete sahip erkek ve kadın bireylerin cinsel ve/veya duygusal yönelimi olarak tanımlanmaktadır. Erkek eşcinsel bireye "gey", kadın eşcinsel bireye "lezbiyen” adı verilmektedir (KAOS GL, 2007: 128). İnsanlığın var olduğundan bugüne kadar olan süreçte bütün insan topluluklarında, coğrafi konuma, tarihe ve kültüre bakılmaksızın bireylerin kendi cinsinden olan kişilere karşı duyduğu cinsel dürtünün bulunduğuna dair araştırmalara rastlanmaktadır (Spencer, 1996; Vicinus vd., 2001: 247; Jilma-Stohlawetz vd., 2001).

Heteroseksüellik, kişinin karşı cinsten bir bireye duyduğu romantik ve duygusal çekiciliğidir. Toplumlarda büyük oranda yer alan norm heteroseksüelliktir. "Heteros" kelimesi Yunanca'da "diğer parça" ile "sexualis" Latince'de "cinsel" kelimesinin birleşiminden oluşmuştur (Macionis, 2017:196). Cinsel yönelim olarak sadece heteroseksüelliği kabul eden ve diğer cinsel yönelimleri kabul etmeyen, baskılayan ya da aşağılayan görüş heteroseksizm olarak tanımlanmaktadır (Güner vd., 2011: 20). Bu kavram, dünyanın heteroseksüel olması gerektiğine dair net bir varsayımdır (Patulny ve Pini, 2013: 121) ve toplumsal cinsiyetin kadına ve erkeğe atfettiği rollerin dışına çıkılmasının doğru olmadığını ve bunun bir kural olduğunu ortaya koymaktadır (Alden ve Parker, 2005: 324).

Biseksüellik, birden fazla cinsiyete karşı duygusal, romantik ve/veya cinsel çekicilik yaşayan veya cinsel ilişkiye giren bir kişiyi tanımlamak için kullanılır. Bununla birlikte, biseksüelliğin bilimsel literatürde yeterince temsil edilmediği ve biseksüellerin lezbiyen, gey ve heteroseksüel topluluklar arasında görünmez olduğu, yok sayıldığı düşünülmektedir (Israel ve Mohr, 2004; Li, Dobinson, Scheim ve Ross, 2013; Vencill ve Israel, 2018:1). Bu yüzden biseksüelliği basitçe tanımlama sorunu bulunmaktadır. Çoğu araştırmacı biseksüelliği her iki cinsiyete karşı erotik yanıt verme modeli olarak görmektedir, ancak bu geniş 
kavramsallaştırma bile birçok soruyu cevapsız bırakmaktadır (Rust, 2002:1679; Diamond, 2008:5)

Literatürde cinsiyet kimliği ve cinsel yönelim (eşcinsellik-heteroseksüellik-biseksüellik) dişında yer alan trans kavramı, doğduklarında kendilerine atanan cinsiyetlerinden farklı cinsiyet kimliğine sahip kişiler için kullanılan kapsayıcı bir kavramdır. Trans kavramı kadınsı, erkeksi olarak belirtilen cinsiyet ifadelerine dair toplumsal beklentiler ile atanmış cinsiyeti çatışan kişiler için kullanılır (Bornstein, 1998; Elkins ve King, 1996; Wilchins, 1997, 2002). Transeksüeller trans kadınlar, trans erkekler, travestiler olmak üzere geniş bir kimlik yelpazesine sahiptir (Bornstein, 1998; Wilchins, 1997, 2002; Bilodeau, 2005: 30). Transseksüellik, ICD (Uluslararası Hastalık Sınıflandırması)'e göre “doğumla ortaya çıkan cinsiyetin tam tersi bir cinsiyet mensubu olarak yaşamak ve kabul edilmek isteği" olarak tanımlanır. Biyolojik erkeğin kadın cinsiyetinin bir üyesi olma; biyolojik kadının ise erkek cinsiyetin bir üyesi olma arzusudur (Hembree vd.,2009:3134). Transeksüel bireyler genellikle biyolojik cinsiyetinden rahatsızlık duyar ve bu cinsiyete ait olmadığını düşünür. Bu bireyler seçtiği cinsiyete uygun hale gelmek için hormonal ve/veya cerrahi tedavi/müdahale görmek ister veya görmüştür. Güner vd.(2011)'e göre travestilik cinsiyet kimliği veya cinsel yönelim değildir. Kadın gibi giyinen bir erkek travesti kendisini erkek olarak tanımlayabilir ya da travesti bir birey heteroseksüel, eşcinsel veya biseksüel olabilir. Kısacası travestilik yalnızca öteki cinsiyet gibi giyinmektir (Güner vd., 2011: 20).

\section{LGBT TÜKETICİ DAVRANIŞLARI}

1990'lardan itibaren kullanılan LGBT kısaltması, Lezbiyen, Gey, Biseksüel ve Trans (travesti ve transseksüel) kavramlardan oluşmaktadır. Azınlık cinsel yönelimi veya transeksüel kimliği olarak ifade edilen (Almeida, 2009;1001) LGBT, toplumda görünmezlikten çıkmaya başlamış ve birçok tartışmayı beraberinde getirmiştir. Turizm ve eğlence sektörleri LGBT'yi ayrı bir pazar bölümü olarak kabul ederken, diğer sektörlerde LGBT birey dikkate alınmamaktadır. Fugate (1993) makalesinde, eşcinsellerin pazar segmenti olarak düşünülemeyeceğini, çünkü bu grubun tanımlanamayacağını, erişilebilir olmadığını ve yeterli büyüklükteki geleneksel kriterleri karşılamadığını iddia etmektedir (Fugate, 1993; Peñaloza, 1996). Foucault (1990), eşcinsel erkek nüfusunun bir kısmının cinsel tercihlerini kıyafet, davranış, konuşma tarzı ile açıkça ifade ettiğini, çoğunluğun ise kendini gizlediğini, benzer şekilde lezbiyenlerin de birçoğunun cinsel yönelimlerini gizlediğini ve erkek eşcinsellerden farklı şekilde sosyalleştikleri için tanımlanmalarının zor olduğunu belirtmiştir. Buna karşılık Hughes (2006:1), gey ve lezbiyen tüketicileri ayrı bir pazar bölümü olarak kabul etmek gerektiğini ifade etmiş ve hedeflenmeye değer bir grup insan olarak tanımlamıştır. Oakenfull (2018:105) LGBT topluluğunu bir pazar bölümü olarak kabul etmenin, bölümün bütün üyelerinin ortak bir tercih ve davranışlar dizisine sahip olduğunu varsayacağını; halbuki bunun LGBT segmenti için yanıltıcı bir önerme olacağını belirtmiştir. Bhat (1996) ise cinsel yönelimin, bir bölümlendirme faktörü olmaktan çok, demografik bölümlendirme içinde "tanımlayıcı" olarak hizmet edebileceğini savunmuştur.

LGBT bireylerin bölümlendirme çalışmalarına ilişkin farklı görüşler bulunmakla birlikte, bu konuda karar vericilerin sektör ve ürün bazında farklılıkları dikkate alan çalışmalar yapması gerekmektedir. Burada pazarlamacıların karşılaşacağı temel sorun, pazar bölümlendirmede önemli olan erişilebilirlik ve ölçülebilirlik kriterlerinin LGBT bireyler için sağlanmasının zor 
olmasıdır. Bütün bu zorluklara rağmen LGBT farkındalığındaki ve kabul görme oranlarındaki artış göz önüne alındığında, bu popülasyonun giderek büyüyen bir pazar bölümü olduğu kabul edilmelidir. "The Marketing The Rainbow" adlı bir tez üzerine çalışan pazarlama uzmanı Alfred Verhoeven ABD'de eşcinsel evliliklerin yasallaşmasından sonra, LGBT bireylere yönelik ticari ürünlerin sayısında ciddi bir artış olduğunu ifade etmiştir (Özkan, 2018). Sonuçta LGBT bireylerin karşılanacak istek ve ihtiyaçları olan, harcayacak geliri bulunan tüketici grupları olduğu gözardı edilmemelidir.

LGBT tüketicilerin sahip olduğu satın alma gücü beraberinde literatüre yeni kavramlar kazandırmıştır. Gey ve lezbiyenlerin harcama gücünü ifade etmek için "pembe dolar", "pink capitalism" veya "pink money" gibi kavramlar ortaya çıkmıştır (Hughes, 2006: 2). Bunun yanısıra eşcinsel tüketicilerin bulunduğu pazar, "Dream Market (Rüya Pazarı)" olarak adlandırılmıştır (Kates, 1998; Peñaloza, 1996; Wardlow, 1996, Oakenfull, 2018:105). Eşcinsel pazarı ya da Peñaloza ve Price'ın (1993) dediği gibi “Dream Market” genellikle yeni bir fenomen olarak görülmekte, gey toplulukları ve gey hareketleriyle beraber büyümektedir. Yeni toplumsal yapıyı beraberinde getiren kentleşme süreci, tarihsel olarak gey pazarının büyümesine etki etmiştir. Bunun nedeni kırsal toplumun cinsellikle ilgili aşırı muhafazakâr zihniyete sahip olması, aksine kentsel gelişmenin şehirleri eşcinseller için sı̆̆ınak haline getirmesidir (Aldrich, 2004; Branchik, 2002; Pereira, \& Ayrosa, 2012).

Büyük şehirlerde kurulan LGBT birlikleri, bu topluluğun örgütlenme çabaları ve birlikte hareket etme isteği şehirlerde alt kültür olarak kendini göstermektedir. Eşcinsel segmenti artık kendi başına bir alt kültür olarak kabul edilmektedir. Bir kültüre veya alt kültüre üyelik kişinin bilişsel yapısını, bu da kişinin eylemlerini ve davranışlarını etkiler, bu yüzden gey tüketiciler gibi altkültürel segmentleri hedefleyen firmalar, alt kültürlerin baskın kültüre kıyasla farklı özelliklere sahip olup olmadığını değerlendirmelidir (Brodowsky 2008;234235). Brodowsky (2008), eşcinsellerin ve heteroseksüellerin farklı bilişsel ve farklı bedensel yapılara sahip olduğunu, dolayısıyla onların farklı tüketici davranışları sergileyebileceklerini kabul etmek gerektiğini ifade etmektedir.

LGBT bireyler ile heteroseksüel bireylerin tüketici olarak farklılığını ortaya koyan çalışmalar mevcuttur. Vandecasteele (2009:136) çalışmasında, eşcinsellerin heteroseksüellere göre daha yüksek eğitimli ve daha fazla harcanabilir gelire sahip olduğunu ve daha yenilikçi davrandıklarını belirtmiştir. Özellikle gey erkeklerin daha yüksek gelire sahip olduğu, daha çok boş zamanlarının bulunduğu ve daha fazla harcama yapma eğilimi gösteren tutumlar sergilediği konusunda bir fikir birliği vardır (Stormbreak, 2000; Hughes, 2006: 2). Bu grupların sözde çocuk yapmaması nedeniyle, kısmen farklı harcama kalıplarına yöneldiği ve farklı bakış açılarına sahip olduğu düşünülmektedir (Stormbreak, 2000; Hughes, 2006: 2).

Eşcinsel erkeklerin satın alma gücü perakendeciler ve pazarlamacılar tarafından tanınan bir pazar segmentidir. Araştırmacıların, eşcinsel tüketicilerin heteroseksüel tüketicilere göre daha fazla gelire sahip olup olmadığı tartışmalarına rağmen (Cronin, 1993; Lukenbill, 1998), eşcinsel tüketicilerin kendi ürün tercihleri bulunduğunu ve harcamaya daha istekli olduğunu gösteren çalışmalar mevcuttur (Johnson, 1993; Fugate, 1993; Rudd, 1996). Heteroseksüeller ile eşcinsel tüketiciler arasındaki farklılığı ortaya koymaya yönelik yapılan araştırmaların bazıları, görünüşün eşcinsel erkekler için (Sergios ve Cody, 1986), heteroseksüel erkeklerden daha önemli olduğunu göstermiştir (Pope vd., 2000, Morrison vd., 
2004;). Eşcinsel erkeklerin kendilerini dış görünüşleri ile ifade etme imkânı bulması, onları alışverişe ve harcamaya daha fazla eğilimli tüketici haline getirmiş olabileceği düşünülebilir.

Tüketici araştırmalarının birçoğu kadın tüketicilere odaklanmıştır. Genellikle ruh hallerini onarmak veya beden imajı hakkındaki olumsuz duyguları hafifletmek için yaptıkları kozmetik, giyim harcamaları erkek tüketicilerden daha fazladır (Corbett, 2000; Elliot, 2000; Dodd, 2005: 376). Clark (1995:484), tüketim kültürünün heteroseksüel normları dikkate alarak geliştiğini, lezbiyenlerin de heteroseksüel kadınlar gibi tüketici olduğunu, giyim, ev eşyası vb. ürünlerin alıcısı olduğunu vurgulamaktadır. Bununla birlikte lezbiyenler gerek reklamlarda gerekse medyada kapitalizmin baskın konfigürasyonu içinde ayrı bir tüketici grubu olarak hedef alınmamıştır. Lezbiyenler heteroseksüel kadınlardan farklıdır ve bu fark, lezbiyenler ile tüketim kültürü arasındaki ilişkiye dikkatli bir şekilde bakmayı gerektirmektedir (Clark 1995:484). Anlamlı ve büyük bir pazar bölümü olarak kabul edilen kadın tüketiciler arasındaki cinsel yönelim farklılıklarına odaklanmak, firmaların pazardaki değişikliklere uyum sağlamalarını kolaylaştıracaktır. Oakenfull (2012:976) geleneksel cinsiyet rollerine daha fazla bağlı olan heteroseksüel kadınlara göre lezbiyenlere daha geniş bir ürün yelpazesi sunmanın yeni pazar fırsatları doğuracağını belirtmiştir.

Diğer araştırmalar ağırlıklı olarak "erkeklik" tanımındaki potansiyel değişime ve kimlik üzerindeki etkisine odaklanmaktadır. Bu çalışmalar, tüketim mallarının tercih edilmesinde geleneksel cinsiyet rollerini ve beklenen davranışları ortaya koymaya yöneliktir (Craik, 1994). Bununla birlikte, yalnızca cinsiyete odaklanmak, dikkati diğer olası göstergelerden uzaklaştırabilir. Dodd vd. (2005), yalnızca heteroseksüel erkek tüketicileri anlamaya çalışmanın, erkek eşcinsel tüketicilerin değerini gözardı ettiğini; ancak eşcinsel erkeklerin dişi özelliklere sahip olduğunu ve ağırlıklı olarak erkek alışveriş ortamı içinde yaşamak zorunda bulunduğunu dikkate almak gerektiğini ifade etmektedir (Dodd vd., 2005: 377)

Günümüzde toplumun ve araştırmacıların LGBT farkındalığının artmasıyla birlikte, firmaların pazarlama faaliyetleri bakımından tutundurma çalışmalarında daha fazla oranda gey ve lezbiyenleri konu edindiği görülmektedir. Oakenfull (2012:968)'a göre son on yılda, LGBT tüketici harcama modellerinin çekiciliğinin kurumsal olarak ortaya konulması, LGBT odaklı tanıtım faaliyetlerinde çarpıcı bir artışa yol açmıştır. Son yıllarda eşcinsel erkekler televizyon programlarında, film ve dizilerde daha fazla yer almakta, bazı firmalar tarafından gey/lezbiyenler için medyada reklam verilmektedir. Eşcinseller kendilerine destek olduklarını düşündükleri firmalara daha çok değer vermektedir. Kates (2004)'in ifade ettiği gibi "Toplumlar tarafından dışlanmış olan tüketiciler, firmalar kendilerine ilgi gösterdiğinde güçlü bir marka sadakati gösterir ve derinden etkilenir" (Kates, 2004: 455).

Literatür taraması sonucunda, tüketici davranışlarını tespit etmeye yönelik araştırmaların birçoğunda biyolojik cinsiyet değişkeninin sıklıkla ele alındığı, cinsel yönelimi dikkate alan çalışmaların daha az olduğu görülmüştür. Oysa Dünyada ve Türkiye'de LGBT bireyler azınlık durumunda olmalarına rağmen sayılarında veya görünürlük oranlarında artış gözlenmektedir. Medyanın etkisi, LGBT derneklerinin faaliyetleri ve toplumda homofobik davranışın nispeten azalması ile LGBT daha fazla konuşulur hale gelmiştir. Dünyada ve Türkiye'de yapılan çalışmalar incelendiğinde LGBT bireyin araştırmaya değer bir grup olduğu, tüketici davranışlarının incelenmesi gerektiği düşünülmüştür. 


\section{METODOLOJi}

Büyüyen bir pazar bölümü olarak kabul edilen LGBT bireylerin tüketici davranışlarını ve tüketici olarak karşılaştıkları sorunları tespit etmek hem akademisyenler hem de pazarlama uygulayıcıları için gereklidir. LGBT bireylerin genellikle kendilerini gizlemeleri ve zor ulaşılan tüketici grubu olması bu araştırmanın önemini artımaktadır. Araştırmanın amacı LGBT bireylerin satın alma tarzlarını tespit etmek, kozmetik, giyim ve eğlence harcama davranışını değerlendirmek, tüketici olarak hetoroseksüel bireyler ile farklılıklarını ortaya koymaktır. Harcama kalemlerinin kozmetik, giyim ve eğlence olarak belirlenmesinin nedeni, LGBT bireylerin bu tür harcamalarla kendilerini ifade etme imkânı bulmalarıdır. Kates (2013:1) kişinin eğlence mekanlarına giderek, belirli giysiler giyerek alenen etiketlenebileceğini ve bunun gey /lezbiyenliğin açığa çıkma deneyiminin bir şekli olduğunu ifade etmiştir.

Araştırmanın amacı doğrultusunda iki temel araştırma sorusu belirlenmiştir;

> Heteroseksüel tüketiciler ile LGBT tüketicilerin satın alma karar verme tarzları hangi boyutlarda farklılık gösteriyor?

Heteroseksüel tüketiciler ile LGBT tüketicilerin aylık kozmetik, giyim ve eğlence harcamaları farklılık gösteriyor mu?

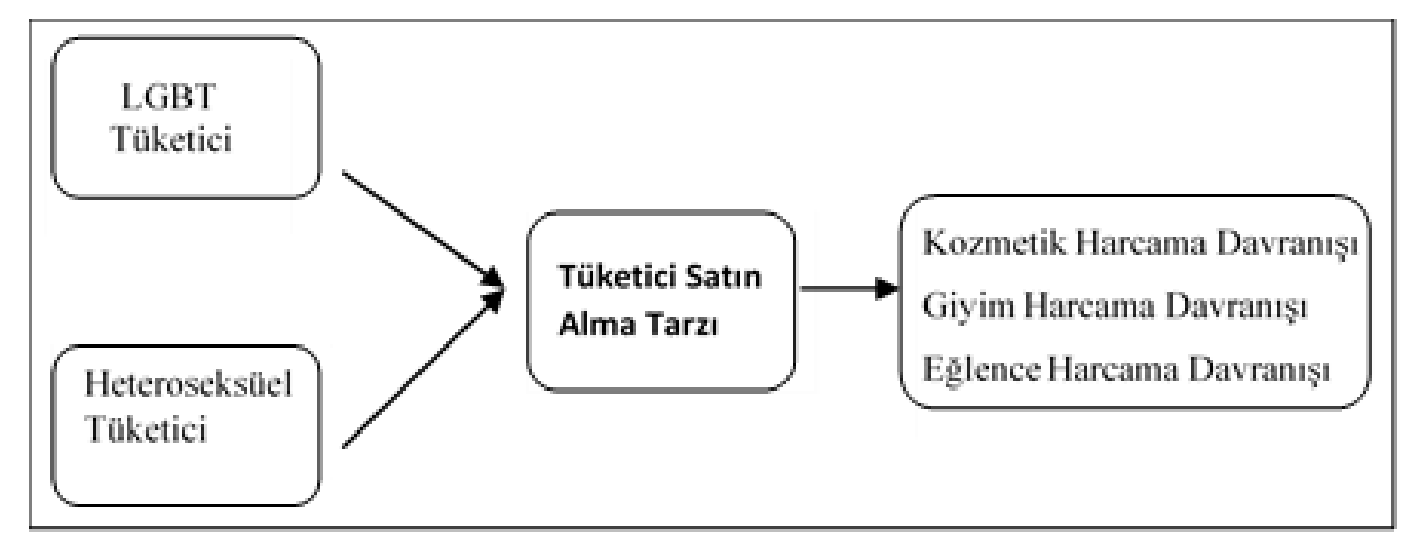

Şekil 1: Araştırmanın modeli

\subsection{Veri Toplama Araçları}

Araştırmada verilerin toplanmasında anket yöntemi kullanılmış, Sproles ve Kendall (1986) tarafından geliştirilen, Aydın (2017) tarafından Türkçe'ye uyarlanan Tüketici Karar Verme Tarzları Ölçeği'nden yararlanılmıştır. Anket formunda ayrıca katılımcıların aylık giyim, kozmetik ve eğlence harcamalarını tespit etmeye yönelik sorulara yer verilmiştir. Toplanan verilerde ölçeklerin güvenirliğini test etmek için iç tutarlılık analizi yapılmıştır. Araştırma modelinde yer alan, tüketici karar verme tarzları ölçeğinin boyutlarının iç tutarlılık katsayısı Tablo 1'de verilmiştir. 
Tablo 1. Tüketici Karar Verme Tarzı Ölçek Boyutlarının İç Tutarlılık Katsayıları

\begin{tabular}{|c|c|c|}
\hline \multirow{4}{*}{$\begin{array}{c}\text { Tüketici Karar Verme } \\
\text { Tarzları Ölçeği }\end{array}$} & Boyutlar & Cronbach Alfa $(\boldsymbol{\alpha})$ \\
\cline { 2 - 3 } & Yüksek Kalite Odaklılık & 0,884 \\
\cline { 2 - 3 } & Marka Odaklılık & 0,784 \\
\cline { 2 - 3 } & Moda Odaklılık & 0,796 \\
\cline { 2 - 3 } & Haz Odakllılk & 0,884 \\
\cline { 2 - 3 } & Fiyat Odaklılık & 0,606 \\
\cline { 2 - 3 } & Çeşit Karmaşası Yaşama & 0,823 \\
\cline { 2 - 3 } & Marka Sadakati & 0,651 \\
\hline
\end{tabular}

Araştırmanın evreni LGBT tüketiciler olarak belirlenmiştir. İzmir Genç LGBT Derneği, Lambdaİstanbul LGBT Dayanışma Derneği, Ankara KAOS-GL Derneği ile görüşülmüş; dernek yönetimleri üye bilgilerini açıklamakta çekince gösterdikleri için "kartopu örneklem yöntemi" tercih edilmiştir. Kartopu örnekleme yöntemi, örnekleme ulaşmanın zor olduğu durumlarda kullanılır, çekirdek cevaplayıcılar tespit edilir ve onların vasitasıyla yeni cevaplayıcılara erişim sağlanır (Nakip,2003: 187). Katılımcıların daha rahat cevap vermesi düşüncesiyle anket uygulaması online ortamda gerçekleştirilmiştir. Anket formunda katılım ifadelerinin cevaplandırılmasında 5'li Likert tutum ölçeğinden yararlanılmıştır. Katılımcıların \%40'ı anketi cevaplamayı yarıda bırakmıştır. Araştırmacının LGBT bireyi olmaması nedeniyle katılımcıların sorulardan rahatsızlık duyduğu ve önyargılı bir tutum geliştirdikleri tahmin edilmektedir. Uygulama sonrası 55 LGBT, 57 hetoroseksüel katılımcının cevapları değerlendirmeye alınmıştır.

\subsection{Araştırmanın Bulguları}

Biyolojik cinsiyet dağılımlarına göre katılımcıların \%38,6'sı kadınlardan, \%26,3'ü erkeklerden oluşmaktadır. Katılımcıların \%35,1'i cinsiyetiniz sorusunu cevaplamamıştır (Tablo 2).

Tablo 2. Heteroseksüel Katılımcıların Cinsiyet Dağılımları

\begin{tabular}{|l|l|l|}
\hline Cinsiyet & $\mathbf{N}$ & $\mathbf{\%}$ \\
\hline Kadın & 22 & 38,6 \\
\hline Erkek & 15 & 26,3 \\
\hline Cevapsiz & 20 & 35,1 \\
\hline Toplam & 57 & 100 \\
\hline
\end{tabular}

Katılımclardan 6 kişi “lezbiyen”, 24 kişi “gey”, 18 kişi “biseksüel”, 3 kişi “transseksüel” ve 4 kişi "diğer" (Intersex veya quer) cinsel yönelime sahip olduğunu ifade etmektedir (Tablo 3).

Tablo 3. LGBT Katılımcıların Biyolojik Cinsiyet ile Cinsel Yönelim Dağılımları

\begin{tabular}{|l|l|l|l|l|l|l|}
\hline Cinsiyet & Lezbiyen & Gey & Biseksüel & Transeksüel & Diğer & Toplam \\
\hline Kadın & 6 & 1 & 12 & 1 & 2 & 22 \\
\hline Erkek & 0 & 23 & 6 & 2 & 2 & 33 \\
\hline Toplam & 6 & 24 & 18 & 3 & 4 & 55 \\
\hline
\end{tabular}

Heteroseksüel katılımcıların biyolojik cinsiyetlerine göre satın alma karar verme tarzları arasındaki farklılığı test etmek için Mann-Whitney U testi uygulanmıştır. Ankete katılan heteroseksüel kadınlar ve erkekler arasında "yüksek kalite odaklılı, marka odaklılık, moda odaklılık, haz odaklılık, fiyat odaklılık, düşünmeden alışveriş yapma, çeşit karmaşası yaşama ve marka 
sadakati" boyutlarında istatistiksel olarak anlamlı farklılık olmadığ $(p>0,05)$ tespit edilmiştir (Tablo 4).

Tablo 4. Heteroseksüel Katılımcıların Cinsiyete Göre Satın Alma Karar Verme Tarzları

\begin{tabular}{|c|c|c|c|c|c|c|}
\hline & & Sira Toplamı & $\begin{array}{l}\text { Sura } \\
\text { Ortalamas } \\
1\end{array}$ & $\mathbf{U}$ & $\mathrm{Z}$ & $\mathbf{P}$ \\
\hline \multirow{3}{*}{$\begin{array}{l}\text { Yüksek } \\
\text { Odaklı }\end{array}$} & \multirow{3}{*}{$\begin{array}{l}\text { Kadin } \\
\text { Erkek } \\
\text { Toplam }\end{array}$} & 22 & 18,95 & \multirow[t]{3}{*}{164} & \multirow[t]{3}{*}{$-0,031$} & \\
\hline & & 15 & 19,07 & & & 0,975 \\
\hline & & 37 & & & & \\
\hline \multirow[t]{3}{*}{ Marka Odaklı } & \multirow{3}{*}{$\begin{array}{l}\text { Kadın } \\
\text { Erkek } \\
\text { Toplam }\end{array}$} & 22 & 20,07 & \multirow[t]{3}{*}{141,5} & \multirow[t]{3}{*}{$-0,730$} & \multirow[t]{3}{*}{0,465} \\
\hline & & 15 & 17,43 & & & \\
\hline & & 37 & & & & \\
\hline Moda Odaklı & $\begin{array}{l}\text { Kadın } \\
\text { Erkek } \\
\text { Toplam } \\
\end{array}$ & $\begin{array}{l}22 \\
15 \\
37 \\
\end{array}$ & $\begin{array}{l}17,11 \\
21,77\end{array}$ & 123,5 & $-1,294$ & 0,196 \\
\hline Hedonistik & $\begin{array}{l}\text { Kadın } \\
\text { Erkek } \\
\text { Toplam }\end{array}$ & $\begin{array}{l}22 \\
15 \\
37 \\
\end{array}$ & $\begin{array}{l}20,27 \\
17,13\end{array}$ & 137 & $-0,872$ & 0,383 \\
\hline $\begin{array}{ll}\text { Fiyat } & \text { Odaklı } \\
\text { Tüketici } & \end{array}$ & $\begin{array}{l}\text { Kadın } \\
\text { Erkek } \\
\text { Toplam }\end{array}$ & $\begin{array}{l}22 \\
15 \\
37 \\
\end{array}$ & $\begin{array}{l}19,16 \\
18,77\end{array}$ & 161,5 & $-0,111$ & 0,911 \\
\hline $\begin{array}{l}\text { Düşünmeden } \\
\text { Alışveriş }\end{array}$ & $\begin{array}{l}\text { Kadın } \\
\text { Erkek } \\
\text { Toplam } \\
\end{array}$ & $\begin{array}{l}22 \\
15 \\
37 \\
\end{array}$ & $\begin{array}{l}18,05 \\
20,40\end{array}$ & 144 & $-0,658$ & 0,510 \\
\hline Çeşit Karmaşası & $\begin{array}{l}\text { Kadin } \\
\text { Erkek } \\
\text { Toplam }\end{array}$ & $\begin{array}{l}22 \\
15 \\
37 \\
\end{array}$ & $\begin{array}{l}19,07 \\
18,90\end{array}$ & 163,5 & $-0,047$ & 0,962 \\
\hline Marka Sadakati & $\begin{array}{l}\text { Kadin } \\
\text { Erkek } \\
\text { Toplam }\end{array}$ & $\begin{array}{l}22 \\
15 \\
37 \\
\end{array}$ & $\begin{array}{l}19,86 \\
17,73\end{array}$ & 146,5 & $-0,595$ & 0,552 \\
\hline
\end{tabular}

LGBT katılımcıların (lezbiyen, gey) biyolojik cinsiyetlerine göre satın alma karar verme tarzları arasındaki farklılığı test etmek için Mann - Whitney U testi uygulanmıştır. Ankete katılan heteroseksüel kadınlar ve erkekler arasında "yüksek kalite odaklılı, marka odaklılık, moda odaklılık, haz odaklılık, fiyat odaklılık, düşünmeden alışveriş yapma, çeşit karmaşası yaşama ve marka sadakati” boyutlarında istatistiksel olarak anlamlı farklılık olmadığ $1(\mathrm{p}>0,05)$ tespit edilmiştir (Tablo 5).

Tablo 5. LGBT Katılımcıların Biyolojik Cinsyete Göre Satın Alma Karar Verme Tarzları

\begin{tabular}{|c|c|c|c|c|c|c|}
\hline & & $\begin{array}{l}\text { Sira } \\
\text { Toplamı }\end{array}$ & $\begin{array}{l}\text { Sira } \\
\text { Ortalaması }\end{array}$ & $\bar{U}$ & $\mathrm{Z}$ & $\mathbf{P}$ \\
\hline \multirow{3}{*}{$\begin{array}{l}\text { Yüksek Kalite } \\
\text { Odaklı }\end{array}$} & \multirow{3}{*}{$\begin{array}{l}\text { Lezbiyen } \\
\text { Gey } \\
\text { Toplam }\end{array}$} & 14 & \multirow{3}{*}{$\begin{array}{l}17,00 \\
20,96\end{array}$} & \multirow[t]{3}{*}{133} & \multirow[t]{3}{*}{$-1,063$} & \\
\hline & & 24 & & & & 0,288 \\
\hline & & 38 & & & & \\
\hline \multirow[t]{3}{*}{ Marka Odaklı } & \multirow{3}{*}{$\begin{array}{l}\text { Lezbiyen } \\
\text { Gey } \\
\text { Toplam }\end{array}$} & 14 & \multirow{3}{*}{$\begin{array}{l}21,18 \\
18,52\end{array}$} & \multirow[t]{3}{*}{144,5} & \multirow[t]{3}{*}{$-0,715$} & \multirow[t]{3}{*}{0,475} \\
\hline & & 24 & & & & \\
\hline & & 38 & & & & \\
\hline Moda Odaklı & $\begin{array}{l}\text { Lezbiyen } \\
\text { Gey } \\
\text { Toplam }\end{array}$ & $\begin{array}{l}14 \\
24 \\
38\end{array}$ & $\begin{array}{l}18,00 \\
20,38\end{array}$ & 147 & $-0,639$ & 0,523 \\
\hline
\end{tabular}




\begin{tabular}{|c|c|c|c|c|c|c|}
\hline Hedonistik & $\begin{array}{l}\text { Lezbiyen } \\
\text { Gey } \\
\text { Toplam }\end{array}$ & $\begin{array}{l}14 \\
24 \\
38 \\
\end{array}$ & $\begin{array}{l}16,64 \\
21,17\end{array}$ & 128 & $-1,219$ & 0,223 \\
\hline Fiyat Odaklı & $\begin{array}{l}\text { Lezbiyen } \\
\text { Gey } \\
\text { Toplam }\end{array}$ & $\begin{array}{l}14 \\
24 \\
38 \\
\end{array}$ & $\begin{array}{l}19,16 \\
18,77\end{array}$ & 136,5 & $-1,044$ & 0,296 \\
\hline $\begin{array}{l}\text { Düşünmeden } \\
\text { Alışveriş }\end{array}$ & $\begin{array}{l}\text { Lezbiyen } \\
\text { Gey } \\
\text { Toplam }\end{array}$ & $\begin{array}{l}14 \\
24 \\
38 \\
\end{array}$ & $\begin{array}{l}15,29 \\
21,96\end{array}$ & 109 & $-1,809$ & 0,070 \\
\hline Çeşit Karmaşası & $\begin{array}{l}\text { Lezbiyen } \\
\text { Gey } \\
\text { Toplam }\end{array}$ & $\begin{array}{l}14 \\
24 \\
38 \\
\end{array}$ & $\begin{array}{l}17,25 \\
20,81\end{array}$ & 136,5 & $-0,964$ & 0,335 \\
\hline Marka Sadakati & $\begin{array}{l}\text { Lezbiyen } \\
\text { Gey } \\
\text { Toplam }\end{array}$ & $\begin{array}{l}14 \\
24 \\
38 \\
\end{array}$ & $\begin{array}{l}20,43 \\
18,96\end{array}$ & 155,5 & $-0,400$ & 0,689 \\
\hline
\end{tabular}

Erkek katılımcıların cinsel yönelimlerine göre satın alma karar verme tarzları arasındaki farklılığ1 test etmek için Mann - Whitney U testi uygulanmıştır. Ankete katılan heteroseksüel ve LGBT erkekler arasında "yüksek kalite odaklılık, moda odaklllı, haz odaklllık, fiyat odaklllık, düşünmeden alışveriş yapma, çeşit karmaşası yaşama ve marka sadakati" boyutlarında istatistiksel olarak anlamlı farklılık olmadığı $(\mathrm{p}>0,05)$ tespit edilmiştir. Sadece "marka odaklılık" satın alma tarzında istatistiksel olarak anlamlı farklılık $(\mathrm{p}=0,017)$ bulunmuştur. Heteroseksüel erkek katılımcılar LGBT erkek katılımcılara göre daha marka odaklıdır (Tablo 6).

Tablo 6. Erkek Katılımcıların Cinsiyel Yönelimlerine Göre Satın Alma Karar Verme Tarzları

\begin{tabular}{|c|c|c|c|c|c|c|}
\hline & & $\begin{array}{l}\text { Sira } \\
\text { Toplamı }\end{array}$ & $\begin{array}{l}\text { Sira } \\
\text { Ortalaması }\end{array}$ & $\mathbf{U}$ & $\mathbf{Z}$ & $\mathbf{P}$ \\
\hline \multirow[t]{3}{*}{ Kalite Odaklı } & \multirow{3}{*}{$\begin{array}{l}\text { LGBT Erkek } \\
\text { Heteroseksüel Erkek } \\
\text { Toplam }\end{array}$} & 24 & 19,69 & 172,5 & \multirow[t]{3}{*}{$-0,544$} & \\
\hline & & 16 & 21,72 & & & 0,587 \\
\hline & & 40 & & & & \\
\hline \multirow[t]{3}{*}{ Marka Odaklı } & \multirow{3}{*}{$\begin{array}{l}\text { LGBT Erkek } \\
\text { Heteroseksüel Erkek } \\
\text { Toplam }\end{array}$} & 24 & 16,92 & \multirow[t]{3}{*}{106} & \multirow[t]{3}{*}{$-2,36$} & \multirow[t]{3}{*}{0,017} \\
\hline & & 16 & 25,88 & & & \\
\hline & & 40 & & & & \\
\hline Moda Odaklı & $\begin{array}{l}\text { LGBT Erkek } \\
\text { Heteroseksüel Erkek } \\
\text { Toplam }\end{array}$ & $\begin{array}{l}24 \\
16 \\
40 \\
\end{array}$ & $\begin{array}{l}21,58 \\
18,88\end{array}$ & 166 & $-0,722$ & 0,471 \\
\hline Hedonistik & $\begin{array}{l}\text { LGBT Erkek } \\
\text { Heteroseksüel Erkek } \\
\text { Toplam }\end{array}$ & $\begin{array}{l}24 \\
16 \\
40\end{array}$ & $\begin{array}{l}19,85 \\
21,47\end{array}$ & 176,5 & $-0,432$ & 0,666 \\
\hline Fiyat Odaklı & $\begin{array}{l}\text { LGBT Erkek } \\
\text { Heteroseksüel Erkek } \\
\text { Toplam }\end{array}$ & $\begin{array}{l}24 \\
16 \\
40 \\
\end{array}$ & $\begin{array}{l}21,77 \\
18,59\end{array}$ & 161,5 & $-0,855$ & 0,392 \\
\hline $\begin{array}{l}\text { Düşünmeden } \\
\text { Alışveriş }\end{array}$ & $\begin{array}{l}\text { LGBT Erkek } \\
\text { Heteroseksüel Erkek } \\
\text { Toplam }\end{array}$ & $\begin{array}{l}24 \\
16 \\
40 \\
\end{array}$ & $\begin{array}{l}21,13 \\
18,59\end{array}$ & 177 & $-0,419$ & 0,675 \\
\hline $\begin{array}{l}\text { Çeşit } \\
\text { Karmaşası }\end{array}$ & $\begin{array}{l}\text { LGBT Erkek } \\
\text { Heteroseksüel Erkek } \\
\text { Toplam }\end{array}$ & $\begin{array}{l}24 \\
16 \\
40 \\
\end{array}$ & $\begin{array}{l}18,06 \\
24,16\end{array}$ & 133,5 & $-1,626$ & 0,104 \\
\hline $\begin{array}{l}\text { Marka } \\
\text { Sadakati }\end{array}$ & $\begin{array}{l}\text { LGBT Erkek } \\
\text { Heteroseksüel Erkek } \\
\text { Toplam }\end{array}$ & $\begin{array}{l}24 \\
16 \\
40 \\
\end{array}$ & $\begin{array}{l}21,77 \\
18,59\end{array}$ & 161,5 & $-0,852$ & 0,394 \\
\hline
\end{tabular}


Kadın katılımcıların cinsel yönelimlerine göre satın alma karar verme tarzları arasındaki farklılığ ve LGBT kadınlar arasında "moda odaklılık, haz odaklılık, fiyat odaklılık, düşünmeden alışveriş yapma, marka odaklılık ve marka sadakati" boyutlarında istatistiksel olarak anlamlı farklılık olmadığı $(\mathrm{p}>0,05)$ tespit edilmiştir. "Yüksek kalite odaklılık" $(\mathrm{p}=0,020)$ ve "çeşit karmaşası yaşama" ( $\mathrm{p}=0,034)$ boyutlarında iki grup arasında istatistiksel olarak anlamlı farklılık bulunmuştur. Heteroseksüel kadın katılımcılar LGBT kadın katılımcılara göre daha fazla oranda yüksek kalite odaklıdır ve çeşit karmaşası yaşamaktadırlar (Tablo 7).

Tablo 7. Kadın Katılımcıların Cinsiyel Yönelimlerine Göre Satın Alma Karar Verme Tarzları

\begin{tabular}{|c|c|c|c|c|c|c|}
\hline & & $\begin{array}{l}\text { Sira } \\
\text { Toplamı }\end{array}$ & $\begin{array}{l}\text { Sira } \\
\text { Ortalamas1 }\end{array}$ & $\mathbf{U}$ & $\mathbf{Z}$ & $\mathbf{P}$ \\
\hline \multirow[t]{3}{*}{ Kalite Odaklı } & \multirow{3}{*}{$\begin{array}{l}\text { LGBT Kadın } \\
\text { Heteroseksüel Kadın } \\
\text { Toplam }\end{array}$} & 13 & 12,77 & \multirow[t]{3}{*}{75} & \multirow[t]{3}{*}{$-2,330$} & \\
\hline & & 22 & 21,09 & & & 0,020 \\
\hline & & 35 & & & & \\
\hline \multirow[t]{3}{*}{ Marka Odaklı } & \multirow{3}{*}{$\begin{array}{l}\text { LGBT Kadın } \\
\text { Heteroseksüel Kadın } \\
\text { Toplam }\end{array}$} & 13 & 14,54 & \multirow[t]{3}{*}{98} & \multirow[t]{3}{*}{$-1,542$} & \multirow[t]{3}{*}{0,123} \\
\hline & & 22 & 20,05 & & & \\
\hline & & 35 & & & & \\
\hline Moda Odaklı & $\begin{array}{l}\text { LGBT Kadın } \\
\text { Heteroseksüel Kadın } \\
\text { Toplam }\end{array}$ & $\begin{array}{l}13 \\
22 \\
35\end{array}$ & $\begin{array}{l}18,19 \\
17,89\end{array}$ & 140 & $-0,860$ & 0,932 \\
\hline Hedonistik & $\begin{array}{l}\text { LGBT Kadın } \\
\text { Heteroseksüel Kadın } \\
\text { Toplam }\end{array}$ & $\begin{array}{l}13 \\
22 \\
35\end{array}$ & $\begin{array}{l}17,19 \\
18,48\end{array}$ & 176,5 & $-0,361$ & 0,718 \\
\hline $\begin{array}{l}\text { Fiyat Odaklı } \\
\text { Tüketici }\end{array}$ & $\begin{array}{l}\text { LGBT Kadın } \\
\text { Heteroseksüel Kadın } \\
\text { Toplam }\end{array}$ & $\begin{array}{l}13 \\
22 \\
35 \\
\end{array}$ & $\begin{array}{l}20,00 \\
16,82\end{array}$ & 117 & $-0,912$ & 0,362 \\
\hline $\begin{array}{l}\text { Düşünmeden } \\
\text { Alışveriş }\end{array}$ & $\begin{array}{l}\text { LGBT Kadın } \\
\text { Heteroseksüel Kadın } \\
\text { Toplam }\end{array}$ & $\begin{array}{l}13 \\
22 \\
35 \\
\end{array}$ & $\begin{array}{l}15,58 \\
19,43\end{array}$ & 111,5 & $-1,094$ & 0,274 \\
\hline $\begin{array}{l}\text { Çeşit } \\
\text { Karmaşası }\end{array}$ & $\begin{array}{l}\text { LGBT Kadın } \\
\text { Heteroseksüel Kadın } \\
\text { Toplam }\end{array}$ & $\begin{array}{l}13 \\
22 \\
35 \\
\end{array}$ & $\begin{array}{l}13,31 \\
20,77\end{array}$ & 82 & $-2,125$ & 0,034 \\
\hline $\begin{array}{l}\text { Marka } \\
\text { Sadakati }\end{array}$ & $\begin{array}{l}\text { LGBT Kadın } \\
\text { Heteroseksüel Kadın } \\
\text { Toplam }\end{array}$ & $\begin{array}{l}13 \\
22 \\
35\end{array}$ & $\begin{array}{l}17,19 \\
18,48\end{array}$ & 132,5 & $-0,363$ & 0,717 \\
\hline
\end{tabular}

Erkek katılımcıların cinsel yönelimlerine göre aylık kozmetik, giyim ve eğlence harcama miktarları arasındaki farklılığı test etmek için Mann - Whitney U testi uygulanmıştır. Ankete katılan heteroseksüel ve LGBT erkekler arasında kozmetik ve giyim harcaması bakımından istatistiksel olarak anlamlı $(p>0,05)$ farklılık olmadığı tespit edilmiştir. Heteroseksüel ve LGBT erkekler arasında aylık eğlence harcaması bakımından istatistiksel olarak anlamlı $(p=0,020)$ farklılık bulunmuştur. LGBT erkek katılımcıların heteroseksüel erkek katılımcılara göre aylık eğlence harcaması daha fazladır (Tablo 8). 
Tablo 8. Erkek Katılımcıların Cinsiyel Yönelimlerine Göre Aylık Kozmetik, Giyim, Eğlence Harcamaları

\begin{tabular}{|l|l|c|c|c|c|c|}
\hline \multicolumn{2}{|l|}{} & $\begin{array}{l}\text { Sira } \\
\text { Toplamı }\end{array}$ & $\begin{array}{l}\text { Sira } \\
\text { Ortalamas } \\
\text { 1 }\end{array}$ & U & Z & P \\
\hline Aylık & LGBT Erkek & 24 & 21,29 & 125 & $-1,319$ & \\
\cline { 3 - 6 } Kozmetik & Heteroseksüel Erkek & 14 & 16,43 & & & 0,182 \\
\hline Aylık & Toplam & 38 & & & & 0,659 \\
Giyim & Heteroseksüel Erkek & 14 & 17,54 & & $-0,441$ & \\
Harcama & Toplam & 36 & & & & 0,047 \\
\hline Aylık & LGBT Erkek & 23 & 22,35 & 107 & $-1,988$ & \\
Eğlence & Heteroseksüel Erkek & 15 & 15,13 & & & \\
Harcama & Toplam & 38 & & & & \\
\hline
\end{tabular}

Kadın katılımcıların cinsel yönelimlerine göre aylık kozmetik, giyim ve eğlence harcama miktarları arasındaki farklılığı test etmek için Mann - Whitney U testi uygulanmıştır. Ankete katılan hem heteroseksüel ve LGBT kadınlar arasında kozmetik, giyim ve eğlence harcaması bakımından istatistiksel olarak anlamlı farklılık $(\mathrm{p}>0,05)$ olmadığı tespit edilmiştir (Tablo 9).

Tablo 9. Kadın Katılımcıların Cinsel Yönelimlerine Göre Aylık Kozmetik, Giyim, Eğlence Harcamaları

\begin{tabular}{|c|c|c|c|c|c|c|}
\hline & & $\begin{array}{c}\text { Sira } \\
\text { Toplamı }\end{array}$ & $\begin{array}{c}\text { Sira } \\
\text { Ortalamasi }\end{array}$ & $\mathbf{U}$ & $\mathbf{Z}$ & $\mathbf{P}$ \\
\hline \multirow{2}{*}{$\begin{array}{c}\text { Aylık Kozmetik } \\
\text { Harcama }\end{array}$} & LGBT Kadın & 13 & 19,77 & \multirow[b]{2}{*}{107} & \multirow[b]{2}{*}{$-1,058$} & \multirow[b]{2}{*}{0,290} \\
\hline & $\begin{array}{c}\text { Heteroseksüel Kadın } \\
\text { Toplam }\end{array}$ & $\begin{array}{l}21 \\
34\end{array}$ & 16,10 & & & \\
\hline $\begin{array}{l}\text { Aylık Giyim } \\
\text { Harcama }\end{array}$ & $\begin{array}{c}\text { LGBT Kadın } \\
\text { Heteroseksüel Kadın } \\
\text { Toplam }\end{array}$ & $\begin{array}{l}14 \\
19 \\
33 \\
\end{array}$ & $\begin{array}{l}18,36 \\
16,00\end{array}$ & 114 & 0,698 & 0,485 \\
\hline $\begin{array}{l}\text { Aylık Eğlence } \\
\text { Harcama }\end{array}$ & $\begin{array}{c}\text { LGBT Kadın } \\
\text { Heteroseksüel Kadın } \\
\text { Toplam } \\
\end{array}$ & $\begin{array}{l}13 \\
19 \\
32 \\
\end{array}$ & $\begin{array}{l}19,04 \\
14,76\end{array}$ & 90,5 & $-1,274$ & 0,203 \\
\hline
\end{tabular}

Katılımcların cinsel yönelimlerine göre (heteroseksüel, LGBT) aylık kozmetik, giyim ve eğlence harcama miktarları arasındaki farklılığı test etmek için Mann - Whitney U testi uygulanmıştır. Ankete katılan heteroseksüel ve LGBT bireyler arasında kozmetik ve giyim harcaması bakımından istatistiksel olarak anlamlı farklılık olmadığ $1(p>0,05)$ tespit edilmiştir. Ankete katılan heteroseksüel ve LGBT bireyler arasında aylık eğlence harcaması bakımından istatistiksel olarak anlamlı $(\mathrm{p}=0,020)$ farklılık bulunmuştur (Tablo 10). LGBT katılımcıların heteroseksüel katılımcılara göre aylık eğlence harcaması daha fazladır. 
Tablo 10. Cinsel Yönelimlere Göre Aylık Kozmetik, Giyim, Eğlence Harcamaları

\begin{tabular}{|c|c|c|c|c|c|c|}
\hline & & $\begin{array}{l}\text { Sira } \\
\text { Toplamı }\end{array}$ & $\begin{array}{l}\text { Sira } \\
\text { Ortalaması }\end{array}$ & $\mathrm{U}$ & $Z$ & $\mathbf{P}$ \\
\hline $\begin{array}{l}\text { Aylık } \\
\text { Kozmetik } \\
\text { Harcama }\end{array}$ & $\begin{array}{l}\text { Heteroseksüel } \\
\text { LGBT } \\
\text { Toplam }\end{array}$ & $\begin{array}{c}54 \\
54 \\
108\end{array}$ & 50,12 & 1221,5 & $-1,470$ & 0,142 \\
\hline $\begin{array}{l}\text { Aylık Giyim } \\
\text { Harcama }\end{array}$ & $\begin{array}{l}\text { Heteroseksüel } \\
\text { LGBT } \\
\text { Toplam }\end{array}$ & $\begin{array}{c}52 \\
53 \\
105\end{array}$ & $\begin{array}{l}50,63 \\
55,33\end{array}$ & 1254,5 & 0,796 & 0,426 \\
\hline $\begin{array}{l}\text { Aylık Eğlence } \\
\text { Harcama }\end{array}$ & $\begin{array}{l}\text { Heteroseksüel } \\
\text { LGBT } \\
\text { Toplam }\end{array}$ & $\begin{array}{c}53 \\
52 \\
105\end{array}$ & $\begin{array}{l}46,24 \\
58,89\end{array}$ & 1019,5 & $-2,318$ & 0,020 \\
\hline
\end{tabular}

\section{SONUÇ}

Heteroseksüel katılımcıların biyolojik cinsiyetlerine göre satın alma karar verme tarzları test edilmiş, kadınlar ve erkekler arasında herhangi bir farklılık bulunamamıştır. Erkek katılımcıların cinsel yönelimlerine göre satın alma karar verme tarzları tüm boyutları ile değerlendirilmiş, sadece "marka odaklılık" boyutunda farklılık tespit edilmiştir. Heteroseksüel erkek katılımcılar LGBT erkek katılımcılara göre daha fazla marka odaklıdır. Miller (1990) gey /lezbiyen tüketicilerin heteroseksüellere göre daha fazla marka ve moda odaklı olduğunu, daha yüksek düzeyde marka sadakati gösterdiğini ortaya koymuştur. Gey ve lezbiyenlerin kendilerine vefalı olan markalara daha sadık olabileceklerini vurgulayan çalışmalar da bulunmaktadır (Miller, 1990; Tuten, 2005, Baxter, 2010:127).

Araştırmada erkek katılımcıların cinsel yönelimlerine göre kozmetik, giyim ve eğlence harcamaları değerlendirildiğinde, LGBT ve heteroseksüel erkek katılımcılar arasında kozmetik ve giyim harcamalarında bir farklılık olmadığı görülmüştür. Bu sonuç literatürle örtüşmemektedir. Eşcinsel erkeklerin, oldukça fazla sayıda kıyafet alışverişine bağımlı davranış düzeyi gösterdiğini, heteroseksüel erkeklere göre daha bağımlı olduğunu iddia eden çalışmalar mevcuttur (Rudd, 1996; Dodd vd. 2005; Reilly vd, 2008: 315). Rudd (1996) çalışmasında, eşcinsel erkeklerin pantolon, gömlek, ceket ve ayakkabı gibi giyim alışverişlerinde heteroseksüel erkeklere göre daha fazla oranda giyim stillerine dikkat ettiği, koku tercihlerinde bile iki grup arasında farklılık gösterdiği sonucuna ulaşmıştır. Hutson, D. J. (2010:228) eşcinsel erkekler için modanın ve dekolte giyimin önemli olduğunu ifade etmiştir.

Ayrıca araştırma kapsamındaki LGBT erkeklerin heteroseksüel erkeklere göre eğlenceye daha fazla miktarda para harcadıkları sonucuna ulaşılmıştır. Bu sonucu doğrulayan çalışmalar mevcuttur. Eşcinseller heteroseksüel bireylere göre seyahatlere (Week 1985), kişisel zevk ve eğlenceye (Rudd 1996:110) daha fazla harcama yapmaktadır. Solomon (1994: 309), eşcinsel gece kulüplerindeki artışa işaret etmektedir. Genel olarak bakıldığında literatürde geylerin ve lezbiyenlerin heteroseksüellere göre daha fazla para harcamaya eğilimli olduğu ifade edilmektedir (Fugate, 1993, Stormbreak, 2000; Hughes, 2006: 2). Eşcinsellerin evlenmeye ve çocuk yapmaya müsait bir yaşam tarzının olmaması, kendilerini daha rahat hissettikleri gey/lezbiyen barlarında sosyalleşmeleri nedeniyle, heteroseksüellere göre eğlenceye daha fazla zaman ve para harcadıkları düşünülebilir. 
Araştırma bulgularına göre heteroseksüel kadın katılımcılar LGBT kadın katılımcılara göre daha yüksek kalite odaklı davranmakta ve daha fazla çeşit karmaşası yaşamaktadır. Literatürde bu sonucu doğrulayan çalışmalara rastlanmamıştır ancak diğer boyutlarda iki grup arasındaki farklılıklara değinilmiştir. Braun (2015) lezbiyenlerin yüksek moda bilincine ve yüksek marka odaklılığa sahip olduğunu ifade etmiştir. Eşcinsel kadınlar ile hetroseksüel kadınlar arasındaki farklıkları açıklamak kolay değildir. Çünkü literatürde yapılan araştırmalar genellikle gey ve lezbiyenleri birarada ele almakta sadece lezbiyenleri dikkate alan az sayıda çalışma bulunmaktadır. Lezbiyen pazarının tanımlanması daha zordur, çoğu lezbiyen cinselliği konusunda daha ihtiyatlıdır ve erkek eşcinsellere göre farklı şekilde sosyalleşmektedir (Miller 1990; Fugate, s.47).

Daha büyük bir örneklem üzerinde çalışıldığında, LGBT tüketicinin satın alma tarzlarında ve harcama davranışında farklı sonuçlar elde edileceği düşünülmektedir. Pazarlamacılar tüketicilerin istek ve ihtiyaçlarında meydana gelen değişiklerin yanısıra LGBT hareketinin yol açtığı değişimi takip etmelidir. Toplumun LGBT bireyi zamanla daha fazla kabulleneceği gerçeğini görmek ve eşcinsel pazarının büyüdüğünü kabul etmek gerekir. Ürün planlamadan tutundurmaya kadar yeni tüketici olarak adlandırılan LGBT bireylerin dikkate alınması, firmaların bölümlendirme çalışmalarında ve pazar araştırmalarında etkinlik sağlayacaktır. Pazar bölümlendirmede cinsiyet faktörünü yalnızca biyolojik cinsiyet değşkenine göre (kadın ve erkek) ele almak, biyolojik cinsiyetini kabul etmeyen LGBT bireylerin varlığını gözardı etmek doğru bir yaklaşım değildir. Pazarlama araştırmacıları anket formu hazırlarken cinsiyet sorusu kısmında "kadın" "erkek" dışında "belirtmek istemiyorum" ya da "queer" (cinsiyet kimliği ve cinsel yönelimleri kapsayan tanım) ibaresine yer vermelidir. Ayrıca pazarlamacılar cinsel yönelim farklılı̆̆ının tüketici davranışına etkisini sektörlerel bazda ortaya koyan araştırmalar yapmalıdır.

\section{KAYNAKÇA}

Alden H. L. and K. F. Parker. (2005). “Gender Role Ideology, Homophobia and Hate Crime: Linking Attitudes to Macro-Level Anti-Gay and Lesbian Hate Crimes". Deviant Behavior, 26 (4), 321-343.

Almeida, J., Johnson, R. M., Corliss, H. L., Molnar, B. E., \& Azrael, D. (2009). Emotional distress among LGBT youth: The influence of perceived discrimination based on sexual orientation. Journal of youth and adolescence, 38(7), 1001-1014.

Aydın, O. (2017). Utangaç tüketici ölçeğinin geliştirilmesi ve tüketici karar verme tarzlarına etkisi.

Baxter, S. C. (2010). Evidence on the marketing approaches targeting gay and lesbian consumers. Global Journal of Business Research, 4(2), 125-139.

Bailey, J. M., Vasey, P. L., Diamond, L. M., Breedlove, S. M., Vilain, E., \& Epprecht, M. (2016). Sexual orientation, controversy, and science. Psychological Science in the Public Interest, 17(2), 45-101.

Barbee, A. P., Cunningham, M. R., Winstead, B. A., Derlega, V. J., Gulley, M. R., Yankeelov, P. A., \& Druen, P. B. (1993). Effects of gender role expectations on the social support process. Journal of Social Issues, 49(3), 175-190. 
Bem, S. L. (1974). "The Measurement Of Psychological Androgyny”, Journal of Consulting and Clinical Psychology, 42/2, 155-162.

Bem, S. L., \& Lenney, E. (1976). Sex typing and the avoidance of cross-sex behavior. Journal of personality and social psychology, 33(1), 48.

Bem, S.L. (1981). “Gender Schema Theory: A Cognitive Account of Sex Typing”, Psychological Review, 88, 354-364.

Bilodeau, B. (2005). Beyond the gender binary: A case study of two transgender students at a Midwestern research university. Journal of Gay \& Lesbian Issues in Education, 3(1), 2944 .

Bornstein, K. (1998). My gender workbook: How to become a real man, a real woman, the real you, or something else entirely. Psychology Press.

Brodowsky, G., Granitz, N., \& Anderson, B. (2008). The best of times is now: A study of the gay subculture's attitudes toward time. Time E Society, 17(2-3), 233-260.

Clark, D. (1995). Commodity lesbianism (pp. 484-500). Duke University Press.

Corbett, G. (2000) 'Women, body image and shopping for clothes', in Baker, A. (ed.) Serious Shopping: Essays in Psychotherapy and Consumerism, Free Association Books, London, UK.

Cronin, H. (1993). The ant and the peacock: Altruism and sexual selection from Darwin to today. Cambridge University Press.

Dembroff, R. A. (2016). What is sexual orientation?. Philosophers' Imprint, January Volume 16, No. 3,1 .

Diamond, L. M. (2008). Female bisexuality from adolescence to adulthood: results from a 10year longitudinal study. Developmental psychology, 44(1), 5 .

Dodd, C. A., Linaker, A., \& Grigg, N. P. (2005). He's gotta have it: Shopping dependence and the homosexual male clothing consumer. Journal of Consumer Behaviour: An International Research Review, 4(5), 374-389.

Dökmen, Z. (2004). Toplumsal Cinsiyet, Sistem Yayıncılık, İstanbul.

Eagly, A. H., Wood, W., \& Diekman, A. B. (2000). Social role theory of sex differences and similarities: A current appraisal. The developmental social psychology of gender, 12, 174.

Elkins, R., \& King, D. (1996). Blending genders: An introduction. In R. Elkins \& D. King (Eds.), Blending genders: Social aspects of cross-dressing and sex changing (pp. 1-4). New York: Routledge.

Elliot, R. (2000) 'Social power, self-identity and addictive consumption', in Baker, A. (ed.) Serious Shopping: Essays in Psychotherapy and Consumerism, Free Association Books, London, UK.

Foucault, M. 1990. The History of Sexuality Vol 1. An Introduction. New York: Vintage. 
Fugate, D. L. (1993). Evaluating the US male homosexual and lesbian population as viable target market segment: Review with implications. Journal of consumer Marketing. 10 (4), 46-57.

Güner, U., Kalkan, P., Öz, Y., Özsoy, E. C., \& Söyle, F. (2011). Türkiye'de Cinsel Yönelim Veya Cinsiyet Kimliği Temelinde Ayrimciliğin İzlenmesi Raporu. Istanbul, Turkey: Insan Haklari Hukuku Uygulama Ve Arastirma Merkezi, Istanbul University.

Hutson, D. J. (2010). Standing out/fitting in: Identity, appearance, and authenticity in gay and lesbian communities. Symbolic Interaction, 33(2), 213-233.

Hembree, W. C., Cohen-Kettenis, P., Delemarre-Van De Waal, H. A., Gooren, L. J., Meyer III, W. J., Spack, N. P., \& Montori, V. M. (2009). Endocrine treatment of transsexual persons: an Endocrine Society clinical practice guideline. The Journal of Clinical Endocrinology \& Metabolism, 94(9), 3132-3154.

Hughes, H. L. (2006). Pink tourism: Holidays of gay men and lesbians. CABI.

Jilma-Stohlawetz, P., Homoncik, M., Drucker, C., Marsik, C., Rot, A., Mayr, W. R., \& Jilma, B. (2001). Fy phenotype and gender determine plasma levels of monocyte chemotactic protein. Transfusion, 41(3), 378-381.

Johnson, B. (1993). The gay quandary: Advertising's most elusive, yet lucrative target market proves difficult to measure. Advertising Age, 64 (18) (January 18) p. 29.

Kagan, J. (1964). Acquisition and significance of sex-typing and sex role identity. In M. L. Hoffman \& L. W. Hoffman (Eds.), Review of child development research (Vol. 1), Russell Sage Foundation, New York.

KAOS, K. G. S. Ç. G., \& Grubu, G. S. Ç.(2011). İşçilerin Eşcinselliğini, Eşcinsellerin İşçiliğini Saklamak Zorunda Kalmayacağı Bir Çalışma Ve Sosyal Hayatı Hedefliyoruz!. TTB Mesleki Sağlık ve Güvenlik Dergisi, 17(65), 35-37.

Kates, S. M. (1998) Twenty Million New Customers. Understanding Gay Men's Consumer Behavior, Haworth Press, New York, NY.

Kates, S. M. (2013). Twenty Million New Customers!: Understanding Gay Meni s Consumer Behavior. Routledge.

Kates, S. M. (2004). The dynamics of brand legitimacy: An interpretive study in the gay men's community. Journal of consumer research, 31(2), 455-464.

Kohlberg, L. A. (1966). Cognitive-developmental analysis of children's sex-role concepts and attitudes. In E. E. Maccoby (Ed.), The development of sex differences, California Stanford University Press, Stanford.

Lombardi, E. L., Wilchins, R. A., Priesing, D., \& Malouf, D. (2002). Gender violence: Transgender experiences with violence and discrimination. Journal of homosexuality, 42(1), 89-101.

Lukenbill, W. B. (1998). Observations on the corporate culture of a gay and lesbian congregation. Journal for the Scientific Study of Religion, 440-452.

Macionis, John J. (2017). Sosyoloji. Nobel Akademik Yayıncılık. 
Miller, C. (1990). Gays are affluent but often overlooked market. Marketing News, 24, 2.

Miller, C. (1992). Mainstream marketers decide time is right to target gays. Marketing News (July 20), p. 8

Morrison, M. A., Morrison, T. G., \& Sager, C. L. (2004). Does body satisfaction differ between gay men and lesbian women and heterosexual men and women?: A meta-analytic review. Body image, 1(2), 127-138.

Nakip, M., (2003). Pazarlama Araştırmaları Teknikler ve (SPSS Destekli) Uygulamaları 1.Baskı, Seçkin Yayıncilık, Ankara.

Oakenfull, G. (2012). Gay consumers and brand usage: The gender-flexing role of gay identity. Psychology \& Marketing, 29(12), 968-979.

Oakenfull, G. W. (2018). Lesbian Consumers and the Myth of an LGBT Consumer Market. Feminist Perspectives on Advertising: What's the Big Idea.

Özkan, Yusuf (2018), BBC Türkçe, https://www.bbc.com/turkce/haberler-dunya-44999996 (Erişlim: 28.05.2021)

Patulny, R., \& Pini, B. (2013). Counting men: Quantitative approaches to the study of men and masculinities. In Men, masculinities and methodologies (pp. 115-128). Palgrave Macmillan, London.

Pereira, S. J. N., \& Ayrosa, E. A. T. (2012). Between two worlds: an ethnographic study of gay consumer culture in Rio de Janeiro. BAR-Brazilian Administration Review, 9(2), 211-228.

Peñaloza Lisa PhD (1996). We're Here, We're Queer, and We're Going Shopping!, Journal of Homosexuality, 31:1-2, 9-41.

Pope, H. G., Phillips, K. A., \& Olivardia, R. (2000). The Adonis complex: The secret crisis of male body obsession. Simon and Schuster.

Reilly, A., Rudd, N. A., \& Hillery, J. (2008). Shopping behavior among gay men: Issues of body image. Clothing and Textiles Research Journal, 26(4), 313-326.

Rudd, N. A. (1996). Appearance and self-presentation research in gay consumer cultures: Issues and impact. Journal of Homosexuality, 31(1-2), 109-134.

Rust, P. C. R. (2002). Bisexuality: The state of the union. Annual review of sex research, 13(1), 180-240.

Segal, R.L.(1992). "Neuromuscular compartments in the human biceps brachii muscle", Neurosci Lett, 140, 98-102.

Sergios, P., \& Cody, J. (1986). Importance of physical attractiveness and social assertiveness skills in male homosexual dating behavior and partner selection. Journal of Homosexuality, 12(2), 71-84.

Solomon, M. R. (1994). Consumer Behavior: Buying, Having and Being. 2 nd Ed., Massachusetts: Paramount Publishing. 
Spencer, B. (1996). Normative context of sexual behaviour and choice of prevention strategies. In M. Bozon, \& H. Leridon (Eds.). Sexuality and Social Sciences -An analysis of the French Social Behavior Survey. London: Dartmouth, forthcoming.

Sprotles, G. B., \& Kendall, E. L. (1986). A methodology for profiling consumers' decision-making styles. Journal of Consumer Affairs, 20(2), 267-279.

Vandecasteele, B., \& Geuens, M. (2009). Revising the myth of gay consumer innovativeness. Journal of Business Research, 62(1), 134-144.

Vencill, J. A., \& Israel, T. (2018). Shining a light into the darkness: Bisexuality and relationships.

Vicinus, M. (2001). "The gift of love": Nineteenth-century religion and lesbian passion. Nineteenth Century Contexts, 23(2), 241-264.

Wardlow, D. L. (Ed.). (1996). Gays, lesbians, and consumer behavior: Theory, practice, and research issues in marketing. Psychology Press.

Wilchins, R. A. (1997). Read my lips: Sexual subversion and the end of gender. Ithaca, NY: Firebrand Books.

https://www.dw.com/tr/dünyada-eșcinselligin-kabul-görme-orant-artıyor/a-53942107 (Erişim: 28.05.2021) 